(C)2016, Elsevier. Licensed under the Creative Commons Attribution-NonCommercialNoDerivatives 4.0 International http://creativecommons.org/about/downloads

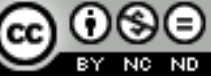




\title{
Assessing and calibrating the ATR-FTIR approach as a carbonate rock characterization tool
}

\author{
Delano G Henry ${ }^{1 *}$, Jonathan S Watson ${ }^{2 \dagger}$ and Cédric M John ${ }^{1 \neq}$ \\ ${ }^{1}$ Department of Earth Science and Engineering and Qatar Carbonate and Carbon Storage Research \\ Centre, Imperial College London, London, SW7 2AZ, UK. \\ ${ }^{2}$ Department of Earth Science and Engineering, Imperial College London, London, SW7 2AZ, UK.
}

Abstract: ATR-FTIR (attenuated total reflectance Fourier transform infrared) spectroscopy can be used as a rapid and economical tool for qualitative identification of carbonates, calcium sulphates, oxides and silicates, as well as quantitatively estimating the concentration of minerals. Over 200 powdered samples with known concentrations of two, three, four and five phase mixtures were made, then a suite of calibration curves were derived that can be used to quantify the minerals. The calibration curves in this study have an $\mathrm{R}^{2}$ that range from $0.93-$ 0.99, a RMSE (root mean square error) of $1-5 w t \%$ and a maximum error of $3-10 w t \%$. The calibration curves were used on 35 geological samples that have previously been studied using XRD (X-ray diffraction). The identification of the minerals using ATR-FTIR is comparable with XRD and the quantitative results have a RMSD (root mean square deviation) of $14 \%$ and $12 \%$ for calcite and dolomite respectively when compared to XRD results. ATR-FTIR can be deployed in the field for real-time data acquisition of the mineralogy of cores and rock chips and this is achievable as no special sample preparation is required, rapid data collection and easy analysis.

Key words: ATR-FTIR; Infrared Spectroscopy; Qualitative Analysis; Quantitative Analysis; Mineralogy; Carbonates.

\section{Introduction}

\footnotetext{
*delano.henry@imperial.ac.uk

† jonathan.watson@imperial.ac.uk

† cedric.john@imperial.ac.uk
} 
Constraining the mineralogy of rocks is common practice in geology. However, current qualitative and quantitative analysis of minerals are often time consuming and expensive, involving extensive sample preparation and lengthy experimental and evaluation time. Common techniques for qualitative and quantitative mineral analysis include staining and modal analyses (counting over 300 points) using thin sections that require skilled and experienced petrologists on the optical microscope, as well as lengthy sample preparation for the thin sections ${ }^{1-3}$, and XRD (X-ray diffraction) that requires lengthy sample preparation and experimental time ${ }^{4,5}$. Here, we present an old technology that is commonly used in most sciences, ATR-FTIR, which we propose is an underused tool in applied geology, as a rapid and more economical tool for qualitative and quantitative analysis of the mineralogy of carbonates.

ATR-FTIR has many applications in geology, environmental science, engineering, agriculture, material science, pharmaceutical industry and medical industry. Although here we focus on the geological application of ATR-FTIR, which can have a wider use in the petroleum industry, sedimentology, marine geology and engineering geology. In the petroleum industry the FTIR has been used as an alternative qualitative technique to analyse the facies, maturation, degradation and contamination of source rocks, as well as reservoir compartmentalization and the evolution of oils within a reservoir ${ }^{6-10}$. For environmental and engineering geology ATR-FTIR has been used for the identification of sheet silicates e.g. smectite and kaolinite, other silicates and carbonates to identify slip zones that are prone to landslide and slope failure ${ }^{11,12}$ and also to assess the anthropogenic effect on the mineralogy of coasts due to the proximity of factories ${ }^{13}$. Most FTIR studies on non-organic rocks have been qualitative, identifying unique spectra for different minerals ${ }^{14-21}$. However, the few studies that have assessed the quantitative potential of FTIR (but not in any depth) have proved that it can be achieved ${ }^{22-25}$. Therefore we set out to conduct an in depth study assessing both the qualitative and quantitative potential of ATR-FTIR, for the characterization of the mineralogy of carbonate rocks. We did this by creating samples with known mineral concentrations to produce calibration curves using the constant ratio method (CRM) for different mineral absorption peaks in a spectrum. We also assessed how well ATR-FTIR is able to identify multiphase minerals in 
rocks, as this is an important step for quantitative analysis, as each mineral mixture will have a different calibration curves. The calibration curves were then applied to real geological samples and the results were compared with XRD results. ATR-FTIR was chosen over transmission FTIR as it is nondestructive and involves faster sampling that needs no preparation. Whereas, for transmission FTIR, $\mathrm{KBr}$ needs to be measured and mixed in with the sample powder and then pressed into a disks using a hydraulic press, which requires more time and skill.

The basic principle of the FTIR is that when an infrared beam is fired at a sample, the molecular bonds in the sample become excited and vibrate by either stretching or bending, leading to the absorption of light at different wavenumbers in the mid-infrared region $\left(4000-400 \mathrm{~cm}^{-1}\right)$. The absorption of infrared light, a proxy for the vibration of the molecular bonds, is highly sensitive to the chemical composition, crystal structure and bonding of a mineral ${ }^{26}$. Therefore each mineral will absorb infrared light differently. The "fingerprint region" from $600-1600 \mathrm{~cm}^{-1}$ is a common region used for identification ${ }^{27}$, as each mineral has a unique combination of absorption peaks. The typical ATRFTIR spectrum has the absorbance on the $y$-axis and wavenumbers $\left(\mathrm{cm}^{-1}\right)$ on the $\mathrm{x}$-axis, increasing from left to right.

\section{Materials ANd Methods}

\section{$2.1 \quad$ Materials}

The standards used in this study are calcite, dolomite, aragonite, magnesite, anhydrite, gypsum, goethite (c.35\% Fe), quartz, sodium rich montmorillonite (SWy-2), illite (IMT-1), kaolinite (KGa-1b), nontronite (NAu-1) and ripidolite (CCa-2) (Table 1). The clays were supplied by the Clay Minerals Society and their chemical composition are available on their website. The gypsum and anhydrite samples are from Brightling mine in East Sussex and were collected in a previous study ${ }^{28}$. Magnesite was synthesised in the laboratory and goethite was supplied by Sigma-Aldrich. Most of the study concentrates on calcite and dolomite, as they make up c.90\% of all carbonates ${ }^{29}$. The magnesite sample was only used to compare the effect of $\mathrm{Mg}$ on the spectra. The geological samples with the prefix "WN" were provided by Hönig and John and are from Wadi Naqab in the Musandam Mountains 
of the UAE taken from the Shuba Member of the Ghalilah Fomation ${ }^{30}$. Geological samples were also provided by Vandeginste, samples with the prefix "BAE", "BAF", "BAG", "BAH” are from the Khufai Formation in Wadi Bani Awf, Oman ${ }^{31}$, and samples with the prefix "MIST" and "MC" are from the Sahtan Group from Wadi MIstal, Oman ${ }^{32}$. In total, there were 35 samples that all came with XRD data.

\subsection{MethodS}

The Thermo Scientific Nicolet 5700 FTIR spectrometer with a single bounce diamond ATR Smart Orbit accessory and a DTGS KBr detector was used for this study. The clamp needs to be tightened so that the powder is in direct contact with the ATR diamond crystal (Fig. 1). For each background and sample spectrum acquired, 128 scans were performed with an average run time of 150 seconds, as beyond 128 scans the quality of the signal to noise ratio does not improve ${ }^{33}$. ATR-FTIR measured wavenumbers from $4000-500 \mathrm{~cm}^{-1}$ at a resolution of $4 \mathrm{~cm}^{-1}$, however in this study the absorption peaks of interest are in the range $600-1600 \mathrm{~cm}^{-1} 27$.

Over 200 powdered samples with known wt\% concentrations were used, in order to construct calibration curves for two, three and four phase samples. Each calibration curve has at least eight known samples and further samples where used at a later date to see whether or not the calibration curves were consistent. Pressed $\mathrm{KBr}$ discs were also prepared for the transmission FTIR and the calibration curves were compared with ATR-FTIR. For the transmission FTIR each disk was mixed with $>99 \mathrm{wt} \% \mathrm{KBr}$ and $<1 \mathrm{wt} \%$ sample and was pressed using a pressure of two tonnes for two minutes in a $7 \mathrm{~mm}$ holder. After the spectra were acquired for the ATR-FTIR, an automatic baseline correction was performed and the position and heights of the peaks were recorded using the Thermo Scientific ${ }^{\mathrm{TM}}$ OMNIC $^{\mathrm{TM}} 7.3$ software. The positions of the peaks help identify the mineral and the peak heights were used for the constant ratio method (CRM), which is used to construct the calibration curves. The CRM works by finding the relationship between a chosen analyte peak and the peak of another mineral present in the sample, as shown in equation 1.

$$
C R M=C 1 /(C 1+Q 1)
$$


Where $C 1$ is a calcite absorption peak and the chosen analyte peak and $Q 1$ is a quartz absorption peak as seen in Figure 2 . The ratios for the same absorption peaks will then be plotted against different known concentrations of the analyte, producing a calibration curve. The calibration curve can then be used to quantify the concentration a minerals in an unknown rock by performing a CRM.

The root mean square error (RMSE) was calculated to capture the range of error for each calibration curve, as shown in equation 2 .

$$
R M S E=\left(\frac{\sum_{i=1}^{n}\left(y_{i}-y_{e q}\right)^{2}}{n}\right)^{1 / 2}
$$

Where $n$ is the number of samples, $y_{i}$ is the known concentration and $y_{e q}$ is the predicted concentration of the analyte using the calibration curve. The maximum error associated for each calibration curve has also been recorded. The root mean square deviation (RMSD) was also used to calculate the average deviation of the ATR-FTIR quantitative results compared to the XRD quantitative results, as show in equation 3.

$$
R M S D=\left(\frac{\sum_{i=1}^{n}\left(y_{X R D}-y_{A T R-F T I R}\right)^{2}}{n}\right)^{1 / 2}
$$

Where $\mathrm{n}$ is the number of samples, $\mathrm{YXRD}_{\mathrm{X} D}$ are the XRD results and $\mathrm{Y}_{\text {ATR-FTR }}$ are the ATR-FTIR results. Figure 3 shows an example of how two one-phase spectra are used for the identification of minerals in a twophase spectrum.

\section{$3 \quad$ Results}

The unique ATR-FTIR spectra for each standard is presented first along with the symbols used for each absorption peak. Two, three and four phase mixtures along with their calibration curves follow. A list of all the calibration curves can be seen in Appendix 1 and only some samples of representative mineral mixtures are shown in the main text as figures.

\subsection{Single Phases}

The symbols and the positions $\left(\mathrm{cm}^{-1}\right)$ of each mineral peak used for identification in this study are documented in Appendix 2. In some multiphase samples " $\&$ " may be between two peak symbols, such 
as " $C 1 \& A 1$ ", this means that the peaks have merged into a single peak and cannot be differentiated. The peak positions for standards will give the basis for the identification of minerals in multi-phase samples. The spectra for the standards, along with the corresponding symbols used for each absorption peak can be seen in Figure 4 .

Carbonates have a strong and broad asymmetric absorption peak at c. $1300-1500 \mathrm{~cm}^{-1}$ due to the $v_{3}$ asymmetric stretching vibration mode of $\mathrm{CO}_{3}^{-2}$ (Fig. 5) ${ }^{34}$. The peak at c.850-880 $\mathrm{cm}^{-1}$ is the lower amplitude $v_{2}$ asymmetric out of plane vibration mode of $\mathrm{CO}_{3}^{-2}$ and is accompanied by a characteristic notch on the falling limb (Fig. 5). The next major peak at c. $700-746 \mathrm{~cm}^{-1}$ is due to the $v_{4}$ symmetrical in plane bend vibration mode of $\mathrm{CO}_{3}^{-2}$. Aragonite has an extra two noticeable absorption peaks at $592 \mathrm{~cm}^{-}$ ${ }^{1}$ and $1081 \mathrm{~cm}^{-1}$.

The absorption band $1081 \mathrm{~cm}^{-1}$ is also apparent in the other carbonates ranging from c.1000-1100 $\mathrm{cm}^{-}$ ${ }^{1}$, but they are less obvious and therefore will not be taken into consideration. The carbonate spectra show good resemblance with published work ${ }^{35,36}$. Figure 6 also shows that increasing the Mg content will blueshift the $v_{4}$ peaks.

The calcium sulphates used are gypsum and anhydrite. Gypsum is the hydrated form of anhydrite and therefore contains additional $\mathrm{H}_{2} \mathrm{O}$ peaks (Fig. 4). $\mathrm{H}_{2} \mathrm{O}$ peaks are also present at c.3500, however Figure 4 only shows wavenumbers up to $1700 \mathrm{~cm}^{-1}$. The calcium sulphate peaks at $c .1100 \mathrm{~cm}^{-1}$ and c. $670 \mathrm{~cm}^{-1}$ are similar, although anhydrite has an extra peak at $609 \mathrm{~cm}^{-1}$ that can be used as a diagnostic peak, followed by a mutual peak at $592 \mathrm{~cm}^{-1}$. Both spectra show good match to those in Liu et al. ${ }^{37}$.

Clay silicates are more complex than carbonates, calcium sulphates and quartz due to the complicated tetrahedron $\mathrm{SiO}_{4}$ structures that can form and complex chemistries. Nonetheless, there are some common aspects in the ATR-FTIR spectra that can be used to identify clay silicate minerals. Silicates share absorption peaks between c.950-1200 $\mathrm{cm}^{-1}$ (Fig. 4); this may be misleading as calcium sulphates also have peaks in this region. The region between c.720-830 $\mathrm{cm}^{-1}$ has a double peak that varies in magnitude and broadness apart from illite and nontronite, which have more than two, very weak peaks. If peaks are present between c. $720-830 \mathrm{~cm}^{-1}$ as well as between c. $950-1200 \mathrm{~cm}^{-1}$, this may 
imply that silicates are present in the sample. Another common peak for silicates is at the base of the rising $\operatorname{limb}$ for the peaks ranging between $c .950-1200 \mathrm{~cm}^{-1}$, labelled QA, MA, KA, IA, RA and NA. These peaks can be used to help identify silicates, however, they may or may not be apparent at low mineral concentrations. A quick way to differentiate quartz from phyllosilicates is to check whether $\mathrm{H}_{2} \mathrm{O}$ peaks are present between $3200-3700 \mathrm{~cm}^{-1}$ (Fig. 7). These structural $\mathrm{H}_{2} \mathrm{O}$ peaks can also be used for identifying phyllosilicates. Notice that smectites (montmorillonite and nontronite) and ripidolite (chlorite) have a lot of adsorbed $\mathrm{H}_{2} \mathrm{O}$ and that kaolinite has a very sharp structural $\mathrm{H}_{2} \mathrm{O}$ peaks and less absorbed $\mathrm{H}_{2} \mathrm{O}$ (Fig. 7). Overall, the phyllosilicate spectra show some differences compared to Bishop et al. ${ }^{38}$, whereas kaolinite and montmorillonite spectra are virtually identical with Madejova and Komadel ${ }^{39}$, as the samples that were used were the same (from the Clay Minerals Society). This may indicate that calibration curves containing clays may not be universal in all areas and new calibration curves may need to be constructed.

Goethite is the second most common iron oxide after heamatite. It is composed of c. $90 \% \mathrm{Fe}_{2} \mathrm{O}_{3}$ and approximately $10 \%$ absorbed water. The spectrum can be seen in Figure 4 and absorbed water is also present at c. $3100 \mathrm{~cm}^{-1}$, similar to the absorbed water of phyllosilicates. In the fingerprint region, goethite's unique combinations of the Gta, Gt1, Gt2, Gt3 and Gt4 peaks can be used for identification.

\subsection{Multiphase Samples and their Calibration Curves}

\subsubsection{Calcite and Dolomite}

When two carbonates are present in a sample, as seen in the calcite and dolomite spectra (Fig. 8), the $\mathrm{C} 1$ and $\mathrm{D} 1$ peaks and $\mathrm{C} 2$ and D2 merge into one peak, forming C1\&D1 and C2\&D2 respectively. These peaks cannot be used to confidently identify what type of carbonates is present. However, the positions of these merged peaks change depending on the relative concentration a carbonate. Increasing the calcite concentration will redshift the C1\&D1 peak position $\left(c .1400 \mathrm{~cm}^{-1}\right)$ and increasing the dolomite concentration will cause a blueshift. The position of the C2\&D2 peak remains relatively unchanged as dolomite and calcite have similar C2 and D2 positions. For carbonate mineral identification in calcite-dolomite mixtures, we propose to use the $\mathrm{C} 3\left(711 \mathrm{~cm}^{-1}\right), \mathrm{D} 3\left(728 \mathrm{~cm}^{-1}\right)$ and A5 
$\left(700 \mathrm{~cm}^{-1}\right)$ as diagnostic peaks. There are two reasons for this. Firstly because the peaks do not merge into one, even at low concentrations. Secondly, because the peak positions remain stable and are not affected by other minerals. Consequently, our calcite and dolomite calibration curve uses the C3 and D3 peaks and has an $\mathrm{R}^{2}$ of 0.99 , RMSE of $2.3 \mathrm{wt} \%$ and a maximum error $4.5 \mathrm{wt} \%$ (Fig. 8).

\subsubsection{Dolomite and quartz}

The diagnostic D3 peak indicates that dolomite is present and quartz can be identified using the QA, Q1, Q2, Q3 and Q4 peaks (Fig. 9). However, at low concentrations (<5wt\%) the Q1 peak and the adjacent peak towards higher wavenumbers, becomes very small. Nevertheless, the QA, Q3 and Q4 peaks can still be used for identification. Notice that the Q1 peak is stronger than the adjacent peak to the left at high concentrations, however at lower concentrations the adjacent peak becomes stronger. Our dolomite and quartz calibration curve uses the peak ratios D3 and Q1 and has an $\mathrm{R}^{2}$ of 0.99, RMSE of $1.8 w t \%$ and a maximum error of 3wt\% (Fig. 9).

\subsubsection{Calcite, Dolomite and Quartz}

Figure 10 shows various three-phase spectra with different concentrations of calcite, dolomite and quartz. The mineralogy of the three-phase spectrum can be identified with confidence using the peaks D3, C3 and Q4. The three phase-spectra containing 50wt\% calcite shows that with increasing dolomite the strength of the C1\&D1 peak decreases. The spectra containing 50wt\% quartz, shows that higher calcite concentration relative to dolomite has a diminishing effect on all the quartz peaks. A two-step method for the quantification of carbonates is applied in this mixture, as there are two different carbonates present along with a silicate. The first calibration curve estimates the total concentration of carbonates using the ratio of C1\&D1 and Q1 and has an $\mathrm{R}^{2}$ of 0.99 , RMSE of $2.9 \mathrm{wt} \%$ and a maximum error of $6.8 \mathrm{wt} \%$ (Fig. 10). After the total amount of carbonate has been estimated the concentration of calcite and dolomite can be estimated using the ratio C3 and D3. This calibration curve has a weaker relationship with an $\mathrm{R}^{2}$ of 0.94 , RMSE of $4.1 \mathrm{wt} \%$ and a maximum error of $9.1 \mathrm{wt} \%$ (Fig. 10). Therefore, "dolomite $=$ total carbonate - calcite". 


\subsubsection{Calcite, Quartz and Montmorillonite}

Calcite and quartz can be readily identified using the diagnostic peaks C3 and Q4, along with their other associated peaks (Fig. 11). Montmorillonite can be identified due to the presence of two peaks on the rising limb of Q1\&M1 and an extra peak M2. The Q2 and Q3 peaks are characteristic of the quartz spectra (Fig. 4). Our calcite, quartz and montmorillonite calibration curve uses the C2 and Q1\&M1 peaks and has an $\mathrm{R}^{2}$ of 0.98 , RMSE of $2.9 \mathrm{wt} \%$ and a maximum error of $5.7 \mathrm{wt} \%$ (Fig. 11 ). However, there is a potential problem that differentiating between montmorillonite and nontronite may prove to be challenging.

\subsubsection{Calcite, Dolomite, Quartz and Illite}

In this four-phase sample (Fig. 12) two carbonates are present, calcite and dolomite and both of them can be differentiated using the C3 and D3 peaks. Quartz can also be identified confidently using the combination of the QA, Q1, Q2, Q3 and Q4 peaks. The identification of illite is challenging, as the only indications that illite is present is the bulging of the rising limb of the QA peak, the slight deformation of the Q1 peak and a small yet characteristic peak on the falling limb of Q1 that connects with the C2\&D2 peaks at c. $920 \mathrm{~cm}^{-1}$ (compare with calcite, dolomite and quartz spectra, Fig. 10). As with the calcite, dolomite and quartz mixture, a calibration curve for quantifying the total amount of carbonates must be applied first, using the peaks C1\&D1 and Q1\&I1. This calibration curve has an $\mathrm{R}^{2}$ of 0.99 , RMSE of $2.7 \mathrm{wt} \%$ and a maximum error of $5 \mathrm{wt} \%$ (Fig. 12). However, when another calibration curve is created to try and calculate the amount of calcite present, the relationship between the peak ratios and concentration breakdown, and the proportion of calcite and dolomite cannot be estimated quantitatively using the calibration curves (Fig. 12). However, by qualitatively analysing the relative peak heights of C3 and D3 an estimation of the relative abundance of calcite and dolomite can be achieved, e.g. when C3>D3 then assume that the concentration of calcite is greater than dolomite.

\subsection{Detection Limits}


The detection limits of ATR-FTIR for a calcite and dolomite mixtures is c.1wt\% using the C3 and D3 peaks (Fig. 13), however the identification does become challenging and zooming into the D3 and C3 region is advised for more confident analysis.

Stacked calcite and silicate spectra with silicate concentrations of $10-20 w t \%$ and $1-10 w t \%$ can be seen in Figure 14. At concentrations of $10-20 w t \%$ it's hard to differentiate between illite and smectite (montmorillonite and nontronite), however kaolinite, quartz and ripidolite can be identified with confidence. At silicate concentrations of $1-10 w t \%$, identification of silicates becomes more challenging, apart from kaolinite. Nevertheless, with careful analysis, quartz may be identified due to the small bump at QA and a small broad peak at $c .1100 \mathrm{~cm}^{-1}$, which is typical of quartz in low concentrations. Ripidolite may also be inferred as the R1 peak is further to the right at lower wavenumbers than the N1, M1 and I1 peaks. The detection limit for silicates using ATR-FTIR is $1 \mathrm{wt} \%$ (Fig. 15) similar to the carbonates, however unlike the carbonates, it is impossible to identify what silicate it is.

\subsection{Applying the calibration curves to geological samples}

Some of the spectra for the geological samples can be seen in Figure (16). Using the peak positions, as seen in appendix 2, calcite, dolomite, quartz and goethite can be confidently identified. However, in samples WN_156 and MC_24 (Fig. 16) an unknown mineral is present, as the Q1 peak has slightly shifted towards lower wavenumbers and there is a bulge on the falling Q1 limb, as well as another small peak at c.920 $\mathrm{cm}^{-1}$. Comparing this with Figure 12, suggests that this could be illite. For sample WN_159, XRD identified phyllosilicates whereas the ATR-FTIR did not. For several of the samples, ATRFTIR identifies quartz, whilst the XRD did not. XRD and ATR-FTIR also identifies goethite in sample Mist_32. XRD also contains un-quantified results.

After mineral identification, the next step is to quantify the minerals using the calibration curves. The calibration curves chosen for each sample in Figure 16 can be seen in Appendix 3. In total 35 geological samples were quantified and the results where compared with XRD results as seen in Figure 
17. Overall, ATR-FTIR has a RMSD of $14 \%$ for calcite, $12 \%$ for dolomite and $7 \%$ for quartz, when compared with XRD results.

\section{Discussion}

The results show that the identification and quantification of minerals in carbonate rocks can be achieved using ATR-FTIR. However, some of the results disagree with XRD. This disagreement between results is expected, as the powders used for XRD analysis were not available for ATR-FTIR analysis, although the powders do come from the same rock. Furthermore, the aim for ATR-FTIR was to create rapid results, therefore only a small surface area of rock was analysed, whereas for XRD, the bulk sample of the rock was analysed. Therefore, there will be bias in sampling, which will be most evident in heterogeneous samples such as MIST_32. Overall, the quantitative results for ATR-FTIR have a RMSD of $14 \%$ for calcite and $12 \%$ for dolomite when compared with XRD results and $60 \%$ of the ATRFTIR results are within a $10 \%$ error range of XRD ${ }^{40}$. However, when the max error range of $10 \%$ (as calculated in this study) for ATR-FTIR is applied, then $85 \%$ of the samples have overlapping results as seen in Figure 18. Nevertheless, the ATR-FTIR approach is a rapid and cheap alternative for multicomponent analysis of carbonate rocks (e.g. matrix, grains and cements) and for understanding the spatial distribution of mineralogy in carbonates very effectively.

Qualitatively, all carbonates can be identified easily in a spectrum due to their characteristic peaks. The $v_{4}$ peak, c.700-746 $\mathrm{cm}^{-1}$ (e.g. C3 and D3) should be used as the diagnostic peaks for confident carbonate identification as they have stable peak positions and do not merge with other peaks. These peaks can also be used as a proxy for the amount of $\mathrm{Mg}$ content in the carbonate as seen in Figure 6 and therefore, theoretically low and high Mg calcites could be identified. The detection limit for these peaks is c.1wt\% in carbonate mixes (Fig. 13). However, samples containing abundant phyllosilicates may obscure these small diagnostic peaks at low carbonate concentrations of $5-10 \mathrm{wt} \%$. If this is the case, then the other carbonate peaks should be used to determine what type of carbonate is present. Nevertheless, this should rarely occur, as the average concentration of phyllosilicates in carbonates is $<10 \%{ }^{41}$, although marls and lower energy carbonates such as mudstones and wakestones may have 
higher clay fractions. This poses an issue, as the identification of illite, montmorillonite, notronite and ripidolite becomes challenging at concentrations of $<20 \mathrm{wt} \%$ in the fingerprint region (Fig. 14). Kaolinite is an exception as it has strong absorption peaks allowing for confident identification at concentrations of $<5 w t \%$, even in complex three and four phase mixtures. However caution should be taken when kaolinite is present, as the strong kaolinite peaks may obscure other clays that are present. Illite on the other hand, has weak peaks that are influenced a great deal by the presence of other phyllosilicates in the sample. Figure 12, a four-phase sample, shows that even when illite concentrations are greater than or equal to other silicates in a sample, the identification of illite is still challenging when more than one silicate is present. This could be an issue as illite is the most common clay mineral found in carbonates ${ }^{41}$. The identification of other silicates used in this study (quartz, nontronite, montmorillonite and ripidolite) are also challenging below $20 w t \%$ as only a small peak is present where Q1, N1, M1 and R1 would be (Fig. 14). One aspect this study did overlook, is using the structural and absorbed $\mathrm{H}_{2} \mathrm{O}$ peaks (Fig. 7) for more confident identification of clays, which could prove to be better than using the fingerprint region. Nevertheless, if the silicates cannot be identified, we propose to categorize them as "unknown silicates" and then use qualitative analysis to estimate the concentration by comparing the relative heights of different mineral absorption peaks. Later studies using XRD can then be used for more accurate analysis if necessary. The detection limit for silicates is $1 \mathrm{wt} \%$, similar to carbonates (Fig. 15); however, unlike carbonates, identification of silicate is impossible as mentioned previously.

The calibration curves presented in this study can be both linear and non-linear and have an $\mathrm{R}^{2}$ that range from $0.93-0.99$, RMSE of $1.4-5 w t \%$ and a maximum error of $3-10 w t \%$. The linearity does not affect the quality of the calibration curve; therefore both linear and non-linear curves can be used for quantitative analysis. However, an argument could be made that linear calibration curves are better because your error will also be linear. With exponential relationship the error could be very large at low or high concentrations. Calibration curves for two-phase samples are straightforward and easy. Three and four phase samples are also straightforward; however when two carbonates are present in 
a three or more phase sample a two-step approach is applied to quantify the concentration of each carbonate. Firstly, the total amount of carbonates needs to be estimated, and then the amount of a single carbonate can be estimated, as shown in Figure 10. In some complex mixtures as shown in Figure 12, the estimation of the total carbonate concentration is achievable, however the second step fails to produce a usable curve. Nevertheless, the concentration of each carbonate may be assessed qualitatively by comparing the relative heights of the C3, D3 and A5 peaks; e.g. if C3>D3, calcite concentration is greater than dolomite. Qualitative analysis can be extremely useful in scenarios when calibration curves cannot be assigned; such as the scenario just mentioned when a usable second step calibration curve fails and also when the mineralogy cannot be confidently identified.

Three possible hypothesis as to why some of the calibration curves are non-linear can be proposed 1) because the orientation of the clay particles may have been preferentially aligned and/or possible clay coatings around the carbonate grains may have effected the vibration of the minerals 2 ) variation in grain sizes within samples 3 ) different peaks behave differently. To test the first hypothesis, a calibration curve was constructed using transmission FTIR for a mixture that showed a non-linear calibration curve using ATR-FTIR, as the $\mathrm{KBr}$ randomly orientates and distributes the clay particles in the sample. Figure 19 shows that the calibration curve for transmission FTIR plots on the same curve as ATR-FTIR (Fig. 19). This rules out that the preferred orientation of the clay particles and/or clay coatings create a non-linear response. The second hypothesis could be a potential reason as to why some calibration curves are non-linear as the grain size distribution was not analysed, however, it does not explain why the same mixture produces some non-linear and linear curves depending on what peaks are used for the CRM. Finally, the results support the third hypothesis, as different peaks in the spectrum behave differently under various concentrations as seen in Figure 20. When kaolinite concentrations are $>50 \%$ the contours between the $\mathrm{K} 1$ and $\mathrm{K} 2$ peaks are very tight and when the concentrations of kaolinite are $<50 \%$ the contours are wide. This suggests that the K1 and K2 peaks grow non-linearly when kaolinite concentration increases and this is evident in the calibration curves that use these peaks, as they are non-linear (Fig. 21). The K3 and K4 peaks however, are seen to behave 
linearly in Figure 20 and hence they have a linear calibration curve (Fig. 21). This indicates that different peaks in a sample can behave non-linearly (K1 and K2) or linearly (K3 and K4), thus a linear or non-linear calibration curve will depend on which peak ratio is used. Other silicates were also tested in similar positions to $\mathrm{K} 3$ and $\mathrm{K} 4$ and they all produced linear calibration curves and the calibration curves that were constructed using similar positions to K1 and K2 produced non-linear curves. The theoretical physics underlining the reason why these peaks behave differently under different concentrations is beyond the scope of this paper. Some of the calibration curves do not have an origin of zero; this is because the peaks used for the CRM interfere with each other. For example the calibration curve constructed for the calcite and aragonite mixture, uses the peaks C3 and A4, which have the same peak position, therefore when the calcite reaches $0 \%$, the aragonite, A4 peak, is still present.

Nevertheless, ATR-FTIR is a robust method that successfully identifies and semi-quantifies carbonates rapidly in multiphase samples as shown in this study. The disadvantage is that phyllosilicates, when in low concentrations, can be challenging to identify due to the similarity in spectra, which may lead to errors when choosing a calibration curve. Although, when all the minerals can be identified and the calibration curve is available, then the whole process from sample preparation to quantifying the minerals should take on average 5 minutes per sample. This however, may not always be the case, as new mixtures may be identified and therefore new calibration curves may need to be constructed. If the new mineral cannot be identified using ATR-FTIR, then XRD analysis could be used to determine the mineral prior to constructing a new calibration curve. If this is not possible, then, similarly as mentioned before the mineral can be called "unknown" and the analyst can choose to qualitatively identify and estimate the concentration of the carbonate present (without identifying the unknown mineral) by comparing the relative heights of the individual mineral peaks. Another disadvantage may be that a new suite of calibration curves may need to be constructed for new localities for more accurate analysis. As Madejová and Komadel showed that montmorillonites from different locations have opposing spectra due to slight chemical variations ${ }^{39}$, therefore calibration curves may need to 
be re-calibrated. Djomgoue and Njopwouo also observed that the FTIR spectra for clays change depending on whether they have been dried or not ${ }^{42}$. This study however, does use rocks from two different localities in the United Arab Emirates and Oman and the results are consistent.

\section{CONCLUSION}

This study shows that ATR-FTIR is a fast, easy and economical tool for the semi-quantitative analysis of the mineralogy in carbonate rocks, with a RMSD of $14 \%$ for calcite and $12 \%$ for dolomite, compared with XRD results; as well as an $85 \%$ confidence that the error bars for both calcite and dolomite concentrations using ATR-FTIR overlap with XRD. It's emphasized that this method will not replace XRD for confident analysis of phyllosilicates as they have similar spectra when in low concentrations, however it is robust method for the study of multi-components in carbonates and can be a valuable approach for rapid and economical analyses in laboratories to help choose samples that need further more expensive and time consuming detailed analysis. Nevertheless, the main novelty of ATR-FTIR is that it can be used in the field for real time data acquisition of the mineralogy of cores and rock chips to study the vertical and/or lateral trends in mineral abundances; e.g. from wells at a well site when the characterization of reservoir rocks is most important or at an outcrop. This is achievable as identification and semi-quantification of carbonates, calcium sulphates, oxides and silicates in geological samples is possible in $<5$ minutes, due to minimal sample preparation, fast analysis time and fast interpretation of the spectra. This will speed up the process for the characterization of carbonate rocks, which, for the petroleum industry will help minimize decisional making risks and uncertainty early in a field's life cycle. The ATR-FTIR approach also has excellent application to the study of unconventional reservoirs, as it can be used as a proxy to assess the fracability index of shale reservoirs at the rig site itself, by semi-quantifying the concentration of minerals. ATR-FTIR can also be used by environmental and engineering geologist for the study of the mineralogy of potential sites for landslides and slope failures, by delineating slip zones due to the presence and relative abundance of smectite clays against other silicates and carbonates, as smectite clays control sliding processes due to their low frictional strength and water absorbing capacity. 


\section{Acknowledgements}

This study was sponsored by the Qatar Carbonate and Carbon Storage Research Centre (funded by Qatar Petroleum, Shell and Qatar Science \& Technology Park). We thank Martin Hönig, Sunshine Abbott and Dr. Veerle Vandeginste who provided geological rock samples and XRD data.

\section{References}

1 F. Chayes (1956) Petrographic modal analysis: An elementary statistical analysis. Wiley, New York.

2 J. A. D. Dickson, A modified staining technique for carbonates in thin section, Nature, 1965, 205, 587-587.

3 M. W. Hitzman, Routine staining of drill core to determine carbonate mineralogy and distinguish carbonate alteration textures, Mineralium Deposita 1999, 34, 794-798.

4 Hardy, R. \& Tucker, M. (1988) X-ray powder diffraction of sediments. - In: Tucker, M. (ed.): Techniques in sedimentology pg. 191-228, Oxford (Blackwell).

5 Harrison, D. J., Inglethorpe, S. D. J., Mitchell, C. J., Kemp, S. J., Chaodumrong, P. \& Charusribandhu, M. (1998) Procedures for the rapid assessment of limestone resources. BGS Technical Report WC/98/1.

6 A. Permanyer, L. Douifi, N. Dupuy, A. Lahcini \& J. Kister, Application to Western Mediterranean oils, Fuel, 2005 , $84(2-3), 159-168$.

7 O. T. Udo \& E. E. Etuk, Journal of Geochemical Exploration, 1990, 37 (2), 285-300.

8 J. I. L. C. Osu \& B. S. Antia, Journal of Applied Sciences and Environmental Management, 2002, 6 (1), 34-38.

9 G. P. Lis, M. Mastalerz, A. Schimmelmann, M. D. Lewan \& B. A. Stankiewicz, Organic Geochemistry, 2005,36 (11), 1533-1552.

10 J. Chen, P. Luo \& J. Li, Chinese Science Bulletin, 1998, 43 (8), 681-684.

11 B. Udvardi, I. J. Kovács, P. Kónya, M. Földvári, J. Füri, F. Budai, G. Falus, T. Fancsik, C. Szabó, Z. Szalai, J. Mihály, Sedimentary Geology, November 2014, 313, 1-14.

12 W. Jian, Z. Wang, K. Yin, Engineering Geology, September 2009, 108, 86-95.

13 S. Sivakumar, R.Ravisankar, Y. Raghu, A. Chandrasekaran, J. Chandramohan, International Research Journal of Pure \& Applied Chemistry, 2013, 3 (4), 40-46.

14 T. D. Herbert, B. A. Tom, C. Burnett, Geochimica et Cosmochimica Acta, 1992, 56, 1759-1763.

15 C. K. Huang \& P. F. Kerr, The American Mineralogist, 1960, 45, 311-324.

16 G. R. Hunt, Geophysics, 1977, 42, 501-513.

17 G. R. Hunt \& J. W. Salisbury, Modern Geology, 1971, 2, 23-30.

18 G. R. Hunt \& J. W. Salisbury, Modern Geology, 1970, 1, 283-300.

19 G. C. Jones \& B. Jackson, Infrared Transmission Spectra of Carbonate Minerals, Springer, 1993.

20 Y. Liu, A. Wand \& J. J. Freeman, 40 th Lunar and Planetary Conference, 2009.

21 J. Workman \& L. Weyer, Practical guide and spectral atlas for interpretive near-infrared spectroscopy, Boca Raton: CRC Press, 2012.

22 F. B. Reig, J. V. G. Adelantado, \& M. C. M. M. Moreno, Talanta, 2002, 58 (4), 811-821.

23 J. Ji, Y. Ge, W. Balsam, J. E. Damuth \& J. Chen, Marine Geology, 2009, 258 (1-4), 60-68.

24 M. B. Adamu, Nigerian Journal of Basic and Applied Science, 2010, 18 (1), 6-18.

25 S. S. Palayangoda \& Q. P. Nguyen, Oil Shale, 2012, 29 (4), 344-356.

26 C. B. Smith, Fundamentals of Fourier transform infrared spectroscopy (2 $2^{\text {nd }}$ edn), Taylor and Francis Group, Boca Raton (Florida), 2011.

27 R. Kellner, J-M. Mermet, M. Otto, H. Valcárcel \& H. M. Widmer, Analytical chemistry: A modern approach to analytical science (2nd edn), Wiley VCH, Weinheim (Germany), 2004.

28 S. S. Abbott, C. M. John \& A. J. Fraser, Marine and Petroleum Geology, January 2016, 69, 74-93.

29 R. J. Reeder, Reviews in Mineralogy. Mineralogical Society of America, 1983, 11 (394).

30 M. Hönig \& C. M. John, poster and abstract presented at AGU, San Francisco (USA), 2013.

31 V. Vandeginste, C. M. John \& J. Beckert, SPE Reservoir Evaluation and Engineering, 2015, 18, 84-91.

32 V. Vandeginste, C. M. John, T. van de Flierdt \& J. W. Cosgrove, AAPG Bulletin, 2013, 97 (7), 1181-1207.

33 J. Ji, Y. Ge, W. Balsam, J. E. Damuth \& J. Chen, Marine Geology, 2009, 258 (1-4), 60-68.

34 C. E. Weir \& E. R. Lippincott, Journal of Research of the National Bureau of Standards-A. Physics and Chemistry, 1961, 65A (3), 173-183.

35 G. C. Jones \& B. Jackson, Infrared Transmission Spectra of Carbonate Minerals, Springer, Netherlands, 1993.

36 C. K. Huang \& P. F. Kerr, The American Mineralogist, 1960, 45, 311-324.

37 Y. Liu, A. Wang \& J. J. Freeman, presented in part at the $40^{\text {th }}$ Lunar and Planetary Conference, Texas, March, 2009.

38 J. L. Bishop, M. D. Lane, M. D. Dyar \& A. J. Brown, Clay minerals, 2008, 43, 35-54.

39 J. Madejová \& P. Komadel, Clays and Clay minerals, 2001, 49 (5), 410-432.

40 F. M. Ruiz, M. O. Huertas, I. P. Delgado \& J. Smit, Geological Society, London Special Publications, 2001, 183, 149-161.

41 E. Flügel, Microfacies of Carbonate Rocks: Analysis, Interpretation and Application, Springer, Verlag Berlin Heidelberg, 2010.

42 P. Djomgoue \& D. Njopwouo, Journal of Surface Engineered Materials and Advanced Technology, 2013, 3, 275282. 


\section{Table caption}

Table 1. Minerals used for this study.

\section{Figure captions}

Fig. 1 Thermo Scientific Nicolet 5700 - diamond Smart Orbit ATR- FTIR with a clamp tightly pressed on the powder.

Fig. 2 ATR-FTIR spectrum of a known sample with $50 \%$ calcite and $50 \%$ quartz.

Fig. 3 Stacked ATR-FTIR spectra of two one-phase spectra and a two-phase spectrum, showing how the onephase spectra are used to identify the minerals in a two-phase spectrum.

Fig. 4 ATR-FTIR spectra for the standards used to construct the calibration curves, along with their peak symbols.

Fig. 5 Vibrational modes for $\mathrm{CO}_{3}{ }^{2-}$ in carbonates after Weir and Lippincott ${ }^{34}$.

Fig. 6 ATR-FTIR spectra of the carbonate $v_{4}$ peaks, showing how increasing the Mg content, shifts the $v_{4}$ peaks to the left.

Fig. 7 Overlain spectra for the clays, showing the $\mathrm{H}_{2} \mathrm{O}$ peaks at high wavenumbers. It must be noted that these peaks were not used for constructing calibration curves, however they are useful peaks for clay identification.

Fig. 8 ATR-FTIR spectra and calibration curve for a calcite and dolomite mixture.

Fig. 9 ATR-FTIR spectra and calibration curves for a dolomite and quartz mixture

Fig. 10 ATR-FTIR spectra and calibration curves for a three-phase calcite, dolomite and quartz mixture.

Fig. 11 ATR-FTIR spectra and calibration curves for a three-phase calcite, quartz and montmorillonite mixture.

Fig. 12 ATR-FTIR spectra and calibration curve for a four-phase calcite, dolomite, quartz and illite mixture. The bottom calibration curve has no relationship and it cannot be used for quantifying the amount of calcite present in this mixture.

Fig. 13 ATR-FTIR detection limit for calcite and dolomite mixtures.

Fig. 14 Stacked ATR-FTIR spectra showing the challenges involved when trying to identify the silicate, when the silicate concentrations are 10-20\% (left) and 1-10\% (right).

Fig. 15 ATR-FTIR spectra showing the detection limit for silicates in a calcite mixture.

Fig 16. ATR-FTIR spectra for the geological samples, along with the interpreted peaks

Fig. 17 Bar chart comparing XRD (left bars) and ATR-FTIR (right bars) results for the geological samples.

Fig. 18 Top chart: comparison of the calcite concentration for the samples using ATR-FTIR and XRD. Bottom chart: comparison of the dolomite concentration for the samples using ATR-FTIR and XRD. The error bars for the XRD are 10\% and the error bars for the ATR-FTIR are 10\%, which is the max error encountered whilst constructing the calibration curves.

Fig. 19 Calibration curve with plots for both transmission FTIR and ATR-FTIR for a calcite and montmorillonite mixture. 
Fig. 20 Overlain spectra for various mixtures of kaolinite and calcite, showing how the main kaolinite K1 and K2 peaks behave in a non-linear fashion as the kaolinite concentration increases and how the K3 and K4 peaks behave linearly as the kaolinite concentration increases.

Fig. 21 A suite of calibration curves showing that when the ratios are calculated using K1 and K2 peaks the calibration curve is non-linear and when the peaks K3 and K4 peaks are used, the curves are linear.

\section{Appendix captions}

Appendix 1. Full list of calibration curves that were constructed.

Appendix 2. Minerals used and their associated peak symbols and wavenumber positions.

Appendix 3. Calibration curves used on the geological samples. "CS": calcite \& quartz calibration curve; "CDS": calcite, dolomite and quartz calibration \& "CDG": calcite, dolomite and goethite calibration curve. "*": The calibration curve equation produced negative concentrations for calcite and concentrations of over $100 \%$ for dolomite. Therefore the concentrations were estimated qualitatively. 